\title{
Knowledge is power: studying critical incidents in intensive care
}

\author{
Panagiotis Kiekkas*1, Diamanto Aretha², Nikolaos Stefanopoulos' and George I Baltopoulos ${ }^{3}$ \\ See related research by Welters et al., http://ccforum.com/content/15/5/R232
}

\begin{abstract}
Despite their difficult definition and taxonomy, it is imperative to study critical incidents in intensive care, since they may be followed by adverse events and compromised patient safety. Identifying recurring patterns and factors contributing to critical incidents constitutes a prerequisite for developing effective preventive strategies. Self-reporting methodology, although widely used for studying critical incidents, has been criticized in terms of reliability and may considerably underestimate both overall frequency and specific types of them. Promotion of non-

blaming culture, analysis of critical incident reports and development of clinical recommendations are expected to minimize critical incidents in the future.
\end{abstract}

In a previous issue of Critical Care, Welters and colleagues [1] presented a study on the types and frequency of critical incidents in the general ICU. Since most relevant studies have been limited to the investigation of errors, medication-associated or not, it is important that this study had a broader perspective by aiming to cover the entirety of critical incidents. These incidents are associated with compromised care quality and patient safety, while critically ill patients can be particularly susceptible to their consequences.

Critical incidents are difficult to define as a whole. In a previous study, Bracco and colleagues [2] recorded them by using a list of 105 items, including complications, infections, medication errors, falls, and so on. The fivecategory classification used by Welters and colleagues [1] intended to group diverse items under distinct labels.

${ }^{*}$ Correspondence: kiekkpan@otenet.gr

'Nursing Department, Highest Technological Educational Institute of Patras, 1 M. Alexandrou Str., Patras, 263-34, Greece

Full list of author information is available at the end of the article
However, the items under the 'Administration' category, including staffing shortages, limited bed availability, and shortcomings in patient documentation and identification, can hardly be considered as critical incidents themselves; they rather constitute factors contributing to them. Especially ICU understaffing has been associated with high rates of drug administration errors, healthcareassociated infections and postoperative complications in previous studies [3-5].

Despite their potential to negatively affect patient clinical course, most critical incidents are not followed by adverse events. According to Reason's Swiss cheese model [6], adverse events occur when the holes in many layers of system defense line up, that is, their cause is generally multifactorial. On the other hand, adverse events are not always attributed to critical incidents and patient injury may occur during appropriate care (for example, adverse drug events due to allergic reactions). In this context, critical incidents have a less random and more statistically predictable occurrence than adverse events. Therefore, determination of recurring patterns of critical incidents is expected to reveal weak points in the process of care, being thus a research priority. At the same time, identifying types of critical incidents most commonly followed by severe adverse events also seems crucial.

Previous studies on ICU critical incidents have focused on the frequency of their types, personnel-related causes and their consequences for patients. Airway-related incidents have been reported to be the most common, followed by line-related ones [7,8]. Human errors accounted for $55 \%$ of incidents in a study conducted in Hong Kong [8], but did not exceed $31 \%$ in a Swiss study [2]. A total of 280 critical incidents were followed by 4 deaths and major physiological change in $3.6 \%$ of them [7]. As regards human-related incidents, 1 out of 241 was lethal, while the rest significantly prolonged ICU patient stay [2]. Unfortunately, Welters and colleagues [1] did not report any contributing factors or consequences of critical incidents, while it is worth noticing that critical incidents associated with airway and disconnection/leaks were much less common than previously reported. 
The limited reliability of data collected through the self-report method has been previously acknowledged [9]. As regards errors, low report rates are common, either because personnel do not become aware of the error, or due to the fear of punitive action. Voluntary error reporting not only leads to significant underestimation of their overall incidence, but may also be associated with underreporting of specific error types. Errors attributed to individual rather than organizational deficiencies are less likely to be reported due to selfesteem and social desirability bias [10]. Likewise, it seems plausible that not all critical incidents are equally reported; for example, cases of equipment malfunction seem much easier to report than incorrect equipment use. In this case, regional database data can be equally affected by underreporting of specific incident types and can thus not be used to confirm the reliability or representativeness of single-center data.

Seeking for root causes of critical incidents and elucidating the interactions among contributing factors that lead to them are necessary for developing effective prevention strategies. Attention distractions, high personnel workload, lack of drug knowledge and mathematical skills, and communication deficiencies have been reported as primary factors contributing to medication errors [11-13]. Since critical incidents constitute a broader field than errors, many other factors are expected to favor their occurrence, such as inadequate training about equipment use, lack of equipment checks, faulty material use, decreased patient surveillance, and so on. Besides addressing incident-contributing factors, future research is further recommended to establish the associations between specific contributing factors and specific critical incident types, so that targeted prevention can be applied.

Conduction of multicenter studies focusing on ICU critical incidents is strongly recommended for two main reasons. First, because critical incidents generally have a low frequency in a single ICU, their patterns can be more clearly revealed by collecting data from several units [10]. Second, the role of factors supposed to contribute to critical incidents can be more reliably confirmed by comparing data among different units - for example, in case higher critical incident rates are associated with lower staffing levels.

How should we move forward to minimize critical incidents and promote patient safety? Healthcare organizations should systematically learn from small failures to prevent greater and sequential ones [14]. Increased reporting rates of critical incidents can only be achieved within a non-blaming climate, by acknowledging their inevitability, treating them as opportunities for improvement, and encouraging trustful communication among personnel. Gathered data should then be analyzed to allow in-depth understanding of critical incident patterns and healthcare system deficiencies as contributing factors, as well as synthesized into useful knowledge by providing clinical recommendations for prevention. Feedback of this knowledge to personnel through continuous education programs will guide proper redesigning of faulty systems and quality improvement efforts [15].

\section{Competing interests}

The authors declare that they have no competing interests.

\section{Author details}

'Nursing Department, Highest Technological Educational Institute of Patras, 1 M. Alexandrou Str., Patras, 263-34, Greece. ${ }^{2}$ Anesthesiology Department, General Pyrgos Hospital, Sintriada, Pyrgos, 271-00, Greece. ${ }^{3}$ Nursing Department, National and Kapodistrian University of Athens, 123 Papadiamantopoulou Str., Athens, 157-73, Greece.

Published: 9 January 2012

\section{References}

1. Welters DI, Gibson J, Mogk M, Wenstone R: Major sources of critical incidents in intensive care. Crit Care 2011, 15:R232.

2. Bracco D, Favre J-B, Bissonnette B, Wasserfallen J-B, Revelly J-P, Ravussin P, Chiolero R: Human errors in a multidisciplinary intensive care unit: a 1-year prospective study. Intensive Care Med 2001, 27:137-145.

3. Beckmann U, Baldwin I, Durie M, Morrison A, Shaw L: Problems associated with nursing staff shortage: an analysis of the first 3600 incident reports submitted to the Australian Incident Monitoring Study (AIMS-ICU). Anaesth Intensive Care 1998, 26:396-400.

4. Hugonnet S, Chevrolet JC, Pittet D: The effect of workload on infection risk in critically ill patients. Crit Care Med 2007, 35:76-81.

5. Dimick JB, Swoboda SM, Pronovost PJ, Lipsett PA: Effect of nurse-to-patient ratio in the intensive care unit on pulmonary complications and resource use after hepatectomy. Am J Crit Care 2001, 10:376-382.

6. Reason J: Human Error. Cambridge: Cambridge University Press; 1990.

7. Chacko J, Raju HR, Singh MK, Mishra RC: Critical incidents in a multidisciplinary intensive care unit. Anaesth Intensive Care 2007, 35:382-386.

8. Buckley TA, Short TG, Rowbottom YM, Oh TE: Critical incident reporting in the intensive care unit. Anaesthesia 1997, 52:403-409.

9. Ferner RE: The epidemiology of medication errors: the methodological difficulties. Br J Clin Pharmacol 2009, 67:614-620.

10. Kiekkas P, Karga M, Lemonidou C, Aretha D, Karanikolas M: Medication errors in critically ill adults: a review of direct observation evidence. Am J Crit Care 2011, 20:36-44.

11. Fahimi F, Ariapanah P, Faizi M, Shafaghi B, Namdar R, Ardakani MT: Errors in preparation and administration of intravenous medications in the intensive care unit of a teaching hospital: an observational study. Aust Crit Care 2008, 21:110-116.

12. Kopp BJ, Erstad BL, Allen ME, Theodorou AA, Priestley G: Medication errors and adverse drug events in an intensive care unit: direct observation approach for detection. Crit Care Med 2006, 34:415-425.

13. van den Bemt PM, Fijn $\mathrm{R}$, van der Voort PH, Gossen AA, Egberts TC, Brouwers JR: Frequency and determinants of drug administration errors in the intensive care unit. Crit Care Med 2002, 30:846-850.

14. Edmondson $A C$ : Learning from failure in healthcare: frequent opportunities, pervasive barriers. Qual Saf Health Care 2004, 13:ii2-ii9.

15. Mahajan RP: Critical incident reporting and learning. Br J Anaesthesia 2010, 105:69-75.

doi:10.1186/cc10593

Cite this article as: Kiekkas $P$, et al.: Knowledge is power: studying critical incidents in intensive care. Critical Care 2012, 16:102. 